\title{
PENGARUH ROLE MODEL TERHADAP PILIHAN KARIR PADA MAHASISWA FAKULTAS KEDOKTERAN
}

\author{
Fatty Maulidira**, Rizma Adlia Syakurah**, Mariatul Fadilah**, Hendarmin Aulia** \\ * Program Studi Pendidikan Dokter, Fakultas Kedokteran, Universitas Sriwijaya \\ ** Departemen Ilmu Kesehatan Masyarakat dan Kedokteran Komunitas, Fakultas Kedokteran, Universitas Sriwijaya
}

\begin{abstract}
Introduction: Career as a doctor is not finished after graduate from basic medical education and clerkship. It will continue and there are many career options that can be choose, divided into clinician or non-clinician. There are many factors that influencing career choice, and one of them is role model. This research aimed to know how role model influence career choicing at students' of Medical Faculty of Sriwijaya University.

Method: This research is descriptive qualitative research. Data is acquired from Program Studi Pendidikan Dokter students by survey with open questions and in-depth interview.

Results: 293 students become respondents of the survey and 8 students become key informants form in-depth interview. Based from informants, positive role model' criterias are having a good-teaching method, looking good, having a good communication method, good attitude and behavior, skilled, and success in their career so that students want to follow those positive role model. Informants also said that negative role model' criterias are having bad teaching method, bad looking and having bad attittude and behavior so that students don't want to follow role model' trait.

Conclusion: Positive role model can make students interested to follow positve role model' career, and negative role model make students do not want to follow negative role model' trait.
\end{abstract}

Keywords: role model, students' career choices, qualitative study

\section{ABSTRAK}

Pendahuluan: Karir sebagai dokter tidak hanya sebatas menamati pendidikan sarjana kedokteran dan pendidikan profesi. Pemilihan karir kedokteran akan berlanjut, dan karir yang dipilih sangat banyak, dapat terbagi menjadi klinisi atau non-klinisi. Banyak faktor yang dapat mempengaruhi pemilihan karir, salah satunya adalah role model. Penelitian ini bertujuan untuk mengetahui bagaimana pengaruh role model dalam pemilihan karir kedokteran pada mahasiswa Fakultas Kedokteran Universitas Sriwijaya.

Metode: Penelitian ini adalah penelitian deskriptif kualitatif. Data diperoleh dari mahasiswa Program Studi Pendidikan Dokter dengan menggunakan survei dengan pertanyaan terbuka dan wawancara mendalam.

Hasil: Sebanyak 293 orang mahasiswa menjadi responden survei dan 8 orang mahasiswa menjadi informan kunci wawancara mendalam. Menurut informan, kriteria role model positif adalah cara mengajar yang baik, berpenampilan yang baik, cara berkomunikasi yang baik, sikap dan perilaku yang baik, terampil, dan sukses di karirnya sehingga mahasiswa ingin meniru role model positif tersebut. Informan juga berpendapat bahwa kriteria role model yang negatif adalah cara mengajar yang buruk, berpenampilan yang buruk dan sikap juga perilaku yang buruk sehingga mahasiswa tidak mau mengikuti sifat role model tersebut.

Kesimpulan: Role model positif dapat menjadikan mahasiswa tertarik untuk mengikuti karir yang dijalani role model, dan role model negatif menjadikan mahasiswa tidak mau mengikuti sifat role model tersebut.

Kata kunci: role model, pemilihan karir mahasiswa, studi kualitatif

korespondensi: fattymaulidira@gmail.com 


\section{PENDAHULUAN}

Karirsebagaidoktertidakhanyasebatas menyelesaikan pendidikan sarjana kedokteran dan pendidikan profesi. Setelah lulus, pemilihan karir kedokteran pun akan berlanjut. Karir yang dapat dipilih setelah menyelesaikan studi kedokteran sangat banyak. Pemilihan karir ini bahkan menjadi keputusan yang sangat penting, ${ }^{1}$ karena pemilihan karir berdampak pada kehidupan dokter tersebut di masa depan. Karir yang umum dipilih seorang dokter dapat dibagi menjadi 2, yaitu klinisi seperti dokter spesialis atau dokter keluarga, dan non-klinisi seperti administrasi dan manajemen rumah sakit, kedokteran komunitas, serta bidang pendidikan dokter itu sendiri. ${ }^{2}$ Ada juga beberapa dokter yang memilih di bagian yang sama sekali tidak berhubungan dengan dunia kesehatan seperti menjadi pengusaha, artis, ataupun ikut berkecimpung di dunia politik. ${ }^{3}$

Pemilihan karir ini menjadi sangat penting untuk diamati, terutamakarena terjadinyaketidakseimbangan antara satu bidang dengan bidang yang lainnya. ${ }^{4}$ Beberapa bidang menarik minat banyak dokter, tetapi tidak begitu di beberapa bidang lain. Belakangan ini, mungkin akan bertahan untuk beberapa tahun ke depan, karir spesialis memiliki peminat yang banyak. Karir spesialis itu sendiri terdiri dari banyak spesialisasi seperti ilmu penyakit dalam, ilmu bedah, ilmu kebidanan dan kandungan, ilmu kesehatan anak, dan masih banyak spesialisasi lainnya. Akibat dari banyaknya bidang ilmu kedokteran baik spesialis maupun non-spesialis, serta peminat masing-masing bidang yang tidak seimbang, maka distribusi dokter di Indonesia menjadi tidak seimbang. ${ }^{5}$

Ketidakseimbangan distribusi dokter ini cukup merugikan, sedangkan sistem Jaminan Kesehatan Nasional yang sudah dimulai dari Januari 2014 menuntut Indonesia agar memiliki distribusi dokter yang seimbang di setiap layanan primer, sekunder, dan tersier. Pembagian karir dokter akan menentukan kualitas pelayanan kesehatan sendiri, terutama akses, tarif, dan hasil dari pelayanan kesehatan. ${ }^{6}$

Pemilihan karir sendiri dipengaruhi oleh banyak faktor dan faktor-faktor tersebut saling mempengaruhi satu sama lain. Minat dan bakat menjadi alasan utama dalam memilih karir. Bukan itu saja, beberapa faktor yang ikut berperan dalam pemilihan karir seorang dokter adalah prospek karir itu sendiri, seperti penghasilan yang mungkin didapat dari karir tersebut, keseimbangan antara jadwal pekerjaan dan kegiatan di luar pekerjaan, dan persepsi masyarakat mengenai prospek karir yang akan dipilih. ${ }^{7}$

Di antara faktor-faktor tersebut, ada yang dinilai sangat berpengaruh dalam pemilihan karir, yaitu pengaruh role model. Beberapa penelitian menyatakan bahwa adanya role model yang baik ternyata dapat meningkatkan ketertarikan mahasiswa untuk memilih bidang tersebut sebagai salah satu pilihan karir. Penelitian di Amerika Serikat menunjukkan bahwa banyak wanita yang memilih spesialisasi seperti ilmu penyakit dalam dan ilmu kesehatan telinga, hidung, dan tenggorokan karena banyak dokter wanita menjadi role model yang sukses di bidang tersebut, dan kebalikannya di bidang radiologi yang sedikit dokter role model wanita maka sedikit juga mahasiswa kedokteran wanita yang memilih karir menjadi spesialis radiologi. ${ }^{8}$ Selain itu, penelitian yang dilakukan di Irlandia juga menunjukkan hasil yang sangat signifikan bahwa banyak mahasiswa kedokteran yang minat untuk masuk ke spesialis bedah karena tidak hanya prestise tapi karena adanya dokter yang menjadi role model di bidang tersebut. ${ }^{7}$ Di India, ada satu penelitian yang mengatakan bahwa kurangnya role model di bidang kesehatan masyarakat menyebabkan kurangnya minat mahasiswa untuk memilih kesehatan masyarakat sebagai salah satu pilihan karir. ${ }^{9}$ Menurut Gibson, ${ }^{10}$ salah satu tokoh yang sering menjadi role model adalah orang tua, sehingga profesi orang tua dokter mungkin dapat berpengaruh dalam pemilihan karir kedokteran itu sendiri. Oleh karena itu, diperlukan penelitian lebih lanjut mengenai pilihan karir yang diminati oleh mahasiswa kedokteran di Indonesia khususnya di Fakultas Kedokteran Universitas Sriwijaya dan faktor-faktor yang mempengaruhi secara signifikan, terutama peranan role model. Selain itu, perlu diteliti juga bagaimana menjadi role model yang baik sehingga dapat menarik mahasiswa kedokteran untuk melanjutkan karir yang tidak terfokus di satu bidang saja. 


\section{METODE}

Penelitian ini adalah penelitian deskriptif kualitatif. Penelitian ini dilakukan untuk mendapatkan informasi tentang pengaruh role model terhadap pilihan karir pada mahasiswa Fakultas Kedokteran Universitas Sriwijaya menggunakan survei dengan pertanyaan terbuka dan wawancara mendalam. Penelitian dilakukan dari September 2014-November 2014 di Fakultas Kedokteran Universitas Sriwijaya Program Studi Pendidikan Dokter. Populasi pada penelitian ini adalah Mahasiswa Fakultas Kedokteran Universitas Sriwijaya yang menempuh pendidikan sarjana kedokteran dan pendidikan profesi dokter muda dengan teknik pengambilan sampel dilakukan secara purposive sampling. Informan dalam penelitian ini meliputi mahasiswa dengan variasi tingkat pendidikan, gender, dan profesi orangtua. Pengumpulan data dianggap selesai jika penambahan data dan informan tidak lagi memberikan informasi baru dalam analisis.

Survei dengan pertanyaan terbuka dilakukan dengan memberikan beberapa pertanyaan terbuka dan ditujukan untuk seluruh populasi penelitian, yaitu mahasiswa angkatan 2009-2014. Wawancara dilakukan berdasarkan dengan pedoman wawancara, dengan dokumentasi menggunakan recorder dan pencatatan. Dalam menjaga validitas data, dilakukan pengujian secara triangulasi.

\section{HASIL DAN PEMBAHASAN}

Data penelitian dikumpulkan melalui survei terbuka dan wawancara mendalam pada mahasiswa Program Studi Pendidikan Dokter Fakultas Kedokteran Universitas Sriwijaya, baik mahasiswa yang menempuh pendidikan profesi kedokteran yaitu mahasiswa angkatan 2009 dan angkatan 2010 maupun mahasiswa yang menempuh pendidikan sarjana kedokteran yaitu mahasiswa angkatan 2011, angkatan 2012, angkatan 2013, dan angkatan 2014. Responden survei berjumlah 293 orang baik mahasiswa maupun mahasiswi. Sedangkan wawancara dilakukan pada 8 orang informan kunci.

Kriteria role model positif yang paling sering muncul adalah cara mengajar yang baik, penampilan yang baik, dan profesionalitas tinggi. Sedangkan kriteria role model negatif adalah penampilan yang buruk, cara mengajar yang buruk, dan gaya bicara yang buruk.

Tabel 1. Kriteria role model bagi mahasiswa

\begin{tabular}{ll}
\hline Role model positif & Role model negatif \\
\hline Cara mengajar yang baik & Penampilan buruk \\
Profesionalitas tinggi & Gaya bicara yang buruk \\
Memiliki motivasi tinggi & Cara mengajar yang buruk \\
Penampilan sederhana/ rapi & Pemikiran negatif \\
Bijaksana & Menjelekkan orang lain \\
Disiplin & Tidak mau menerima kritik \\
Komitmen & Memiliki reputasi yang buruk \\
Berjiwa muda & Menyulitkan mahasiswa \\
Membaur dengan mahasiswa & Merendahkan mahasiswa \\
Berwawasan luas & Tidak berwibawa \\
Sukses & Terlalu banyak berbicara \\
Percaya diri & Rasis/ subyektif \\
Energik & Mengharapkan imbalan \\
Rendah hati & Humor berlebihan \\
Religius & Sombong \\
Terampil klinis & Merokok \\
Humoris & Kaku \\
Berwibawa & Berbicara bukan bidangnya \\
Berpikir kritis & Tidak bertanggung jawab \\
Motivator & Citra buruk sebagai dokter \\
Prestasi & Setengah hati menjalankan prof \\
Ramah & \\
Banyak pasien & \\
Kemampuan bahasa asing & \\
\hline
\end{tabular}


Berdasarkan wawancara, didapatkan kriteria role model positif adalah sebagai berikut:

a. Penampilan yang baik

Hal ini diungkapkan oleh beberapa informan kunci yang menyatakan bahwa penampilan yang baik menjadi alasan memilih suatu role model positif. Penampilan yang baik adalah sebagai berikut:

"Sederhana, gak ribet, enak aja ngeliatnya. Dan di usianya yang segitu masih seger buger dia itu nunjukin kalo dokter itu bisa jaga kesehatan." (Informan kunci 1)

"Yang baik itu yang rapi, yang nggak urak-urakan, yah namanya kan dokter." (Informan kunci 2)

"Dokter yang baek itu penampilannya bersih, rapi, terus ramah" (Informan kunci 4)

"Penampilan sehari-hari itu pengaruh banget ya, karena dokter itu dilihat dari pertamanya ya penampilannya." (Informan kunci 5)

"Jadi mulai dari pakaian ya pakaian rapi, rambut harus rapi, penampilannya menarik, seperti itu" (Informan kunci 6)

"Yang namanya kita dokter kita kan harus ada pencitraan kan." (Informan kunci 7)

b. Sikap dan perilaku yang baik

Dokter yang memiliki sikap yang baik menjadi salah satu kriteria role model positif. Beberapa informan kunci mengatakan:

"Sikapnya rendah hati, sederhana, dan ngambarin itu dokter banget" (Informan kunci 1)

"Dokter yang kalo menurut saya yang suka mengabdi kepada masyarakat." (Informan kunci 2)

"karena dokter itu bukan dari obat tapi juga dari sikapnya terhadap pasien." (Informan kunci 6)

c. Cara bicara atau berkomunikasi yang baik Beberapa informan menyatakan bahwa dokter yang baik adalah yang memiliki cara bicara atau cara berkomunikasi yang baik. Hal ini diungkapkan oleh beberapa informan kunci sebagai berikut:
"Yang pasti bikin pasien tuh mau kalo berobat sama dia, terus nyaman, terus dia bisa kalo kita dibikin percaya, gak harus bakal sembuh tapi bisa jelasin ke kita, komunikasi yang baik, hubungan dokter pasien yang baik, ada kepercayaan dokter dari pasien." (Informan kunci 1)

"Yang komunikatif dan yang apa yah harus lebih bisa mungkin menghargai orang-orang di sekitarnya, pasien-pasien kan beragam kan, jadi pasti dia tuh seharusnya pemikirannya lebih luas misalnya berbicara seharusnya dipikir terlebih dahulu nggak selalu menjudge sesuatu sesuai yang dia ketahui, tapi dicerna dulu, ditelaah dulu gitu." (Informan kunci 2)

"Jadi gak tertutup, gak pendiam, tapi bisa membawa diri ke masyarakat." (Informan kunci 3)

"Sebagai dokter berarti kita harus berpenampilan meyakinkan bahwa kita itu mampu mengobati pasien, mampu berinteraksi dengan pasien, dan membuat pasien itu percaya pada kita." (Informan kunci 6)

"Yah kalo kita dateng ke dia itu belum berobat aja dah sembuh gitu, yang baik, ramah." (Informan kunci 7)

d. Karir yang sukses

Kesuksesan karir menjadi faktor seorang dokter dijadikan role model bagi mahasiswa. Hal ini disebutkan oleh para informan kunci sebagai berikut:

"Terus dengan karirnya yang sibuk banget di THT, kan kita tahu dokter THT di kita masih sedikit banget dan dengan kesibukannya itu dia masih bisa ikut organisasi. Dia kan ketua IDI, dan ikut organisasi-organisasi sosial, yang berhubungan dengan pendengaran juga." (Informan kunci 1)

"Mungkin karena apa ya dilihat dari masa lampau beliau sampai sekarang ini sudah sukses kan termasuk menginspirasi lah, saya juga salut juga lah dia itu dokter yang tidak mementingkan materi seperti yang saya bilang tadi karena yah punya kerja sampingan kan dia punya sekolah alam kayak gitu jadi lebih, lebih bisa dikatakan mungkin sukses lah.” (Informan kunci 2) 
"Pinter, luar biasa, prakteknya laris." (Informan kunci 8)

e. Memiliki skill yang terampil

Skill yang terampil membuat mahasiswa ingi mengikuti cara dokter tersebut sehingga menjadi salah satu kriteria role model. Hal ini diungkapkan oleh beberapa informan sebagai berikut:

"Yang jelas dokter itu art dan science, dan utama itu adalah art, kenapa art karena science tanpa art kalo di dokter itu gak ada gunanya." (Informan kunci 6)

"Kalo misalnya ngerjain jahit-jahitan cepet, rapi, misalnya gitu ya kita pengennya seperti dia. Kan bagaimana caranya biar kita bisa jadi seperti dia." (Informan kunci 8)

Sedangkan kriteria role model negatif yang didapatkan dari wawancara adalah sebagai berikut:

a. Penampilan yang buruk

Penampilan sehari-hari yang buruk menjadi salah satu kriteria role model yang paling sering diungkapkan oleh beberapa informan. Pernyataan informan mengenai penampilan buruk adalah:

"Menurut aku nggak cocok dokter itu glamourglamour banget, karena menegaskan ke masyarakat kalo dokter itu kaya kaya lah, apalah gitu jadi timbul image negatif kan, terus ada juga dokter yang gak rapi ini juga gak bagus menurut aku." (Informan kunci 1)

"Kalo misalnya dokter aja penampilannya menakutkan mungkin ya pasien atau orang-orang disekitarnya kan nggak percaya juga jadi ya kehilangan kepercayaan dari dokter tersebut." (Informan kunci 2)

"Dia itu dak buruk tapi penampilannyo sedikit tidak mencerminkan dia itu dokter, karena bajunyo kaos, celano jeans, besendal." (Informan kunci 4)

"Soalnya gak ada dokter yang rambutnya panjang preman gitu mana ada kan pasien yang tertarik dan bilang ah kayaknya bukan dokter deh." (Informan kunci 7) b. Cara bicara atau berkomunikasi buruk Dokter yang tidak bisa berkomunikasi dengan baik dinilai sebagai mahasiswa menjadi kriteria role model negatif. Hal ini disebutkan oleh beberapa informan kunci sebagai berikut:

"Yang gak ramah, terus jarang senyum, jadi bikin pasien jadi takut ngeliatnya. Terus juga kalo ketus dan nganggep pasien itu kayak jaman dulu yang hubungan dokter-pasien itu kayak bukan orang yang sederajat gitu, jadi misalnya dia nganggep pasien itu lebih rendah dari dia kan itu gak baik." (Informan kunci 1)

"Cara bicara juga tidak mencerminkan dokter yang menurut saya baik gitu." (Informan kunci 2)

"Orangnya acuh tak acuh, cara dia bicara, cara dia berkomunikasi, semuanya itu mempengaruhi." (Informan kunci 3)

c. Sikap dan perilaku yang buruk

Mahasiswa berpendapat bahwa sikap dan perilaku yang buruk tidak mencerminkan sifat dokter sehingga menjadi salah satu kriteria role model negatif. Hal ini diungkapkan mahasiswa sebagai berikut:

"Tidak mengikutkan hati, jadi kan cuma sebatas profesi, jadi mungkin lebih banyak orientasi ke materi gitu." (Informan kunci 2)

"Sebenarnya dari sikapnya tercermin, dari tindakannya juga, memperlihatkan sesuatu yang sebenarnya tidak pantas untuk ditunjukkan ke orang lain." (Informan kunci 3)

"Yang selengekan..." (Informan kunci 4)

"Dokter tuh melayani pasien dengan jelek, ngomongnya nggak bagus, attittudenya jelek, orang tu gak respect sama dia." (Informan kunci 7)

Pemilihan role model salah satunya adalah dokter yang menjadi orang tua ataupun keluarga dari mahasiswa tersebut. Bahkan mahasiswa tertarik mengikuti karir yang persis sama dengan orang tua atau keluarganya. Hal ini diungkapkan oleh beberapa informan kunci yang orangtuanya atau keluarganya adalah dokter. Mereka menyebutkan bahwa: 
"Saya tahu latar belakang orang tua saya, dari dulu yang merintis dari awal kan, terus ada jatuh bangunnya juga nggak sukses dari awal, dia juga kuliahnya biaya sendiri, buku fotokopi, dan saya percaya bahwa beliau juga tidak mementingkan materi dalam bekerja seperti dokter yang ideal yang dalam pikiran saya." (Informan kunci 2)

"Yah karena orang tua, pengen karir kedepannyo tuh kayak papa saya." (Informan kunci 4)

"Pengen jadi THT atau PDL, karena om dan tante saya yang berada di karir itu, terus obgin juga apalagi sepupu aku yang banyak obgin. " (Informan kunci 5)

"Role model kakak yang utama adalah orang tua, orang tua memang dari FK, obgin, jadi kakak juga sering berinteraksi atau sering mendengar tentang obgin jadi menurut kakak itu seru." (Informan kunci 6)

Dari hasil survei maupun wawancara, didapatkan beberapa kriteria role model positif dan negatif yang menjadi kriteria utama bagi mahasiswa baik yang sedang menempuh pendidikan sarjana kedokteran maupun yang telah menempuh pendidikan profesi.

Cara mengajar yang baik merupakan kriteria role model yang paling dicari oleh mahasiswa. Hal ini sesuai dengan penelitian yang dilakukan oleh Stagg ${ }^{6}$ yang menyatakan bahwa dosen di bidang klinis menjadi salah satu faktor yang mempengaruhi pemilihan karir mahasiswa. Selain itu kriteria lain dokter yang dapat dijadikan role model adalah berpenampilan yang baik, cara berkomunikasi yang baik, sikap dan perilaku yang baik, terampil, dan sukses di karirnya. Hal ini sesuai dengan penelitian yang dilakukan oleh Passi ${ }^{11}$ yang juga menyatakan clinical attributes seperti penampilan, cara berkomunikasi, sikap, perilaku, keterampilan klinis dan kesuksesan karir menjadikan seseorang dapat dijadikan role model.

Sedangkan untuk kriteria role model yang negatif yang paling utama baik pada mahasiswa yang menempuh pendidikan profesi maupun pendidikan sarjana kedokteran adalah cara mengajar yang buruk dan penampilan yang tidak mencerminkan dokter. Berdasarkan wawancara pun para informan juga menyatakan bahwa penampilan dan cara berbicara termasuk cara mengajar merupakan faktor penting yang harus ditampilkan secara baik oleh role model. Selain itu, sikap dan perilaku yang buruk juga menjadi salah satu kriteria role model negatif.

Berdasarkan wawancara dan hasil survei, role model berpengaruh dalam pemilihan karir. Pengaruh dari role model positif dalam mempengaruhi pemilihan karir adalah role model positif dapat memberikan contoh tentang karir itu sendiri. Selain itu, role model positif juga memberikan contoh mengenai penampilan dan gaya bicara yang bagusnya diterapkan dalam dunia kedokteran. Pengaruh dari role model positif lainnya adalah pengalaman karir yang selama ini dijalani oleh role model tersebut. Hal ini sesuai dengan yang dikemukakan oleh Gibson ${ }^{10}$ yang menyatakan role model positif dapat memberikan contoh bagaimana tingkah laku atau sifat yang diharapkan mahasiswa untuk ditiru dan diterapkan di kehidupan seharihari, dan juga mengikuti jejak yang sama dengan role model.

Selain pengaruh dari role model positif, ada juga pengaruh dari role model negatif. Dari hasil survei maupun wawancara mendalam, pengaruh dari role model negatif adalah berupa mahasiswa tidak ingin meniru role model tersebut, bahkan beberapa mahasiswa menyatakan tidak ingin mengikuti jejak karir yang sama dengan role model negatif. Gibson ${ }^{10}$ juga menyatakan bahwa role model negatif adalah role model yang perilakunya maupun sikapnya berusaha untuk dihindari. Begitu juga dengan penelitian yang dilakukan Passi ${ }^{11}$ yang menyatakan bahwa mahasiswa akan berusaha menghindari untuk mengikuti tingkah laku dari role model negatif.

Dari hasil survei maupun wawancara mendalam, orang tua merupakan salah satu role model yang sangat berpengaruh. Dari hasil survei ada beberapa anak dokter yang memilih orang tuanya sebagai role model dan ingin mengikuti jejak karir yang sama dengan orang tua mereka. Tidak hanya orang tua, anggota keluarga lainnya yang juga berprofesi sebagai dokter juga ikut berpengaruh. Sedangkan pada wawacara mendalam, juga ditemukan gambaran yang mirip dengan hasil survei terbuka. Dari 4 informan yang memiliki orang tua dokter, semuanya menyatakan bahwa orang tuanya adalah role model. Bahkan 3 dari 4 informan yang diawancara menyatakan bahwa 
mereka akan memilih karir yang sama dengan orang tua mereka. Informan 2 menyatakan ingin memilih karir sebagai dokter umum atau dokter layanan primer karena ayahnya yang juga berkecimpung di karir tersebut, walaupun hal ini disampaikan secara tersirat oleh informan tersebut. Informan 4 dengan sangat jelas ingin mengikuti karir kedokteran yang sama dengan ayahnya karena sering melihat ayahnya bekerja di karir tersebut sehingga ikut tertarik mengambil karir yang sama. Dan inforan 6 memiliki banyak pilihan karir, namun salah satu pilihan karir yang akan dipilih oleh informan 6 juga adalah pilihan karir yang sama dengan orang tuanya. Sedangkan pada informan 8, informan menyatakan bahwa tidak ingin mengikuti jejak karir spesialis ayahnya namun juga akan mengambil karir spesialis. Dari hasil wawancara mendalam pada informan 5 yang orang tuanya bukan dokter, informan menyatakan tertarik mengikuti karir dokter sejak SMA karena saudara dari orang tuanya yang saat ini menjadi salah satu role model informan ini juga berprofesi sebagai dokter, dan sekarang ingin mengikuti karir spesialis yang sama dengan role model tersebut. Hal ini sesuai dengan yang diungkapkan Gibson ${ }^{10}$ mengenai orang tua menjadi salah satu role model yang berpengaruh.

Pada wawancara mendalam yang dilakukan pada informan yang orang tuanya bukan berprofesi sebagai dokter, mereka memilih karir salah satunya berdasarkan pendapat pribadi dari keluarga mereka. Seperti pada informan 1 yang menyatakan bahwa pemilihan karir yang lebih ke arah spesialis dikarenakan orang tua mereka mengarahkan ke pilihan karir tersebut. Informan 3 juga menyatakan ingin lebih ke arah dokter umum karena keluarganya tidak menginginkan informan untuk melanjutkan ke karir spesialis. Informan 5 memilih karir spesialis karena ada anggota keluarganya yang dokter yang memilih karir spesialis sehingga ingin mengikuti jejaknya. Dan informan 7 juga menyatakan mengikuti ke arah karir spesialis karena orang tuanya mengarahkan ke karir spesialis karena lebih terlihat berprestise tinggi.

Pemilihan role model pada penelitian ini tidak bergantung pada jenis kelamin. Mahasiswa tidak hanya memilih role model dokter pria, begitu juga mahasiswi tidak hanya memilih role model dokter wanita. Role model ini tidak berlaku hanya untuk yang positif namun juga untuk yang negatif. Pada penelitan yang dilakukan Jagsi ${ }^{8}$ juga menunjukkan bahwa jenis kelamin tidak mempengaruhi pemilihan role model dan juga tidak ada hubungan signifikan antara jenis kelamin dengan pemilihan karir.

Pada hasil survei ditemukan bahwa role model positif pada angkatan tertentu dapat menjadi role model negatif di angkatan lainnya. Hal ini menunjukkan bahwa adanya perbedaan pendapat pada mahasiswa yang sudah lebih lama menempuh pendidikan dan yang baru saja masuk ke dunia perkuliahan. Ada beberapa role model dimana pada angkatan yang lebih tua merupakan role model positif namun pada angkatan yang lebih muda merupakan role model negatif. Dan begitu juga ada role model yang pada angkatan lebih muda dinyatakan role model positif namun pada angkatan yang lebih tua dinyatakan role model negatif. Fenomena ini mempengaruhi pemilihan karir sehingga terdapat variasi pemilihan karir yang berbeda pada angkatan yang lebih tua dan yang lebih muda.

Terdapat kontradiksi mengenai persepsi mahasiswa terhadap menilai role model, dimana ada yang menyatakan suatu kriteria dinilai sebagai positif tapi di sisi lain sebagai negatif. Hal ini muncul bisa disebabkan oleh kebiasaan negatif yang dilakukan oleh dosen namun dianggap menguntungkan mahasiswa seperti mengurangi waktu kuliah, memberikan nilai yang tidak seharusnya sehingga muncul ekspektasi yang salah pada mahasiswa.

\section{KESIMPULAN}

Kriteria role model positif bagi mahasiswa Fakultas Kedokteran Universitas Sriwijaya adalah dokter yang memiliki cara mengajar yang baik, berpenampilan yang baik, cara berkomunikasi yang baik, sikap dan perilaku yang baik, terampil, dan sukses di karirnya.

Kriteria role model negatif bagi mahasiswa Fakultas Kedokteran Universitas Sriwijaya adalah cara mengajar yang buruk, berpenampilan yang buruk dan sikap juga perilaku yang buruk.

Role model baik positif maupun negatif berpengaruh dalam pemilihan karir. Role model positif dapat menarik minat mahasiswa untuk mengikuti karir 
yang sama, dan kebalikannya role model negatif menurunkan minat mahasiswa untuk mengikuti sifat role model.

Salah satu role model yang paling banyak berperan adalah orang tua dokter ataupun keluarga yang berkarir di dunia kedokteran.

Role model yang dipilih setiap angkatan berbeda, bahkan role model positif pada mahasiswa angkatan tertentu dapat menjadi role model negatif di mahasiswa angkatan lainnya.

\section{DAFTAR PUSTAKA}

1. Glavin, KW, Richard, GV, \& Porfeli, EJ. Predictive validity of the medical specialty preference inventory. Journal of Vocational Behavior 2009;74:128-133.

2. Richards, P, \& Stockill, S. Learning Medicine: An Informal Guide to A Career in Medicine, $16^{\text {th }}$ edition. London: BMJ Publishing Group; 2003.

3. Reese, Shelly M. 2012. Tired of Being a Doctor? Choices for Opting Out of Medicine. Medscape Business of Medicine [Articles]. (diakses pada tanggal 15 Juli 2014 di http://www.medscape.com/ viewarticle $/ 757765 \quad 3$ )

4. Syakurah, RA, Sari, DA, Riansyah, D, \& Yolanda, P. Determinan pilihan karir mahasiswa fakultas kedokteran sebagai spesialis di Indonesia. Jurnal Pendidikan Kedokteran Indonesia 2014;3(2): 132 136.
5. Konsil Kedokteran Indonesia. Registrasi Keseluruhan Jumlah Dokter/Dokter Gigi Seluruh Indonesia; 2014. (diakses pada tanggal 3 Oktober 2014 di http:// www.kki.go.id/)

6. Scott, A, Joyce, C, Cheng, T, \& Wang, W. Medical career path decision making: an evidence check rapid review for the NSW Ministry of Health. Report by Sax Institute Australia; 2013.

7. Glynn, RW, \& Kerin, MJ. Factors in لuencing medical students and junior doctors in choosing a career in surgery. The Surgeon, Journal of the Royal Colleges of Surgeons of Edinburgh and Ireland 2010;8:187191.

8. Jagsi, R, Griflth, KA, DeCastro, RA, \& Ubel, P. Sex, role model, and specialty choices among graduates of US Medical Schools in 2006-2008. Journal of American College of Surgeons 2014;218(3):345-352.

9. Kumar, R, Singh, A, \& Gupta, SN. Public health as a career option: postgraduate students' perspective. Indian Journal of Preventive Medicine 2013;1(1):2934.

10. Gibson, Donald E. Role model. Dalam: Greenhaus, Jeffrey H. dan Gerard A. Callanan. Encyclopedia of Career Development. Hal 701-703. California: Sage Publications; 2006.

P11. assi, V, Johnson, S, Peile, E, Wright, S, Hafferty, F, \& Johnson, N. 2013. Doctor role modelling in medical education. BEME Guide no. 27. Hal. 1422-1436. 